\title{
Electroclinical features of idiopathic generalised epilepsy with persisting absences in adult life
}

Roberto Michelucci, Guido Rubboli, Daniela Passarelli, Patrizia Riguzzi, Lilia Volpi, Lucio Parmeggiani, Romana Rizzi, Elena Gardella, Carlo Alberto Tassinari

\begin{abstract}
Objectives-To describe the electroclinical features of typical absences persisting in adult life.

Methods-Twelve adult patients (aged 21 to 56 years) with idiopathic generalised epilepsy featuring typical absences as the prominent clinical feature were studied. All patients underwent a full clinical and neurophysiological investigation including ictal documentation of seizures.

Results-Neurological examination and neuroradiological investigations were normal in all cases. Clinical findings included a median age at onset of absences of 14 (range 4-32) years, almost constant tonic-clonic seizures (in $83 \%$ of patients), frequent episodes of absence status (in $33 \%$ of patients), and associated cognitive or psychiatric disturbances. Interictal EEG findings showed normal background activity, generalised paroxysms of spike waves or polyspike waves, and inconstant focal spikes (in five patients); runs of polyspikes were seen during non-REM sleep. Ictal EEG findings showed generalised spike waves at $3 \mathrm{~Hz}$, sometimes preceded by multiple spikes, or more complex EEG patterns with sequences of polyspikes intermingled with spike waves or polyspike waves, showing discharge fragmentation or variation of intradischarge frequency.

Conclusion-The results of the present study show that absences persisting in adult life may show particular clinical and EEG patterns, distinct from those in childhood or adolescence.
\end{abstract}

(F Neurol Neurosurg Psychiatry 1996;61:471-477)

Department of Neurology, University of Bologna, Bellaria Hospital, Bologna, Italy

R Michelucci

G Rubboli

D Passarelli

P Riguzzi

L Volpi

L Parmeggiani

R Rizzi

E Gardella

C A Tassinari

Correspondence to:

Dr Roberto Michelucci,

Department of Neurology,

3, 40139 Bologna, Italy.

Reeived 3 January 1996

and in final revised form

1 July 1996

Accepted 1 July 1996 years. Panayiotopoulos et $a l^{67}$ also described a large population of adult patients with typical absences and provided an accurate syndromic classification of their cases.

We report the electroclinical patterns of 12 adult patients with idiopathic generalised epilepsy, featuring typical absences as the prominent clinical manifestation.

\section{Materials and methods}

During the past five years we found 12 patients meeting the following criteria: $(a)$ age over 20 years; (b) presence of typical absences, as defined by the Commission on Classification and Terminology of the International League Against Epilepsy (ILAE) ${ }^{8}$; (c) clinical and EEG features consistent with the diagnosis of idiopathic generalised epilepsy. ${ }^{9}$ These patients were identified from 1000 consecutive referrals from January 1991 to November 1995 to our epilepsy clinic.

This was a retrospective study in which the patients had a full clinical and neurophysiological investigation including detailed clinical history, neurological and mental examination, CT or MRI of the head, routine EEG, videoEEG (six patients), ambulatory EEG (six patients), and sleep EEG (during afternoon nap). The clinical description of the seizures was obtained by video recording in six patients with daily absences and by witnesses in the remaining patients.

EEGs were performed by using eight to 21 channels with a longitudinal montage. In sleep tracings, ECG, thoracic breathing, and deltoid surface EMG were monitored. Patients were asked to count aloud during hyperventilation, which allowed us to evaluate impairment of consciousness during generalised spike wave discharges. In selected patients a more accurate neuropsychological assessment (including reading and presentation of verbal or visual memory tasks) was required. A Nihon Kohden 21 channel polygraph or an eight channel Micromed Computerised EEG system were used for all the recordings, both during wakefulness and sleep. For video-EEG studies, a split screen instrument combining the recording of the EEG waveforms with the synchronous TV pictures of the patient was used. Ambulatory EEG was accomplished with an Oxford Medilog instrument using seven EEG channels with a longitudinal montage supplemented by ECG.

We examined a total of 49 routine EEG recordings performed at the time of referral at our Institute. In three patients 12 EEGs dating 


\begin{tabular}{|c|c|c|c|c|c|c|c|c|c|c|c|c|c|}
\hline \multirow[b]{2}{*}{ Patient } & \multirow[b]{2}{*}{ Sex } & \multirow{2}{*}{$\begin{array}{l}\text { Family } \\
\text { history }\end{array}$} & \multirow[b]{2}{*}{ Age } & \multicolumn{4}{|c|}{ Age of onset of seizures } & \multicolumn{4}{|c|}{ Frequency of seizures } & \multirow[b]{2}{*}{$\mathrm{Me} / \mathrm{Be}$} & \multirow[b]{2}{*}{ Therapy } \\
\hline & & & & $A b s$ & GTCS & ferks & $A b s S$ & $A b s$ & GTCS & ferks & $A b s S$ & & \\
\hline 1 & $\mathbf{F}$ & - & 28 & 24 & 18 & - & 28 & D & SP & - & 2/life & - & VPA \\
\hline 2 & $\mathrm{~F}$ & - & 25 & 4 & 14 & - & - & $\mathrm{D}$ & Mo & - & - & - & ETS, VPA, PB \\
\hline 3 & $\mathbf{F}$ & - & 49 & 23 & 23 & - & - & W & Mo & - & - & $+\mathrm{Me}$ & $\mathrm{CBZ}, \mathrm{VPA}, \mathrm{PB}$ \\
\hline 4 & $\mathbf{M}$ & - & 56 & 16 & 20 & - & 41 & SP & $2 /$ year & - & $2 /$ year & $+\mathrm{Me}$ & PHT, PB \\
\hline 5 & $\mathbf{M}$ & - & 50 & 32 & 35 & - & - & Mo & $1 /$ life & - & - & - & PB \\
\hline 6 & $M$ & - & 55 & 17 & 27 & - & 55 & D & 4/year & - & 1/life & $+\mathrm{Me}$ & $\mathrm{DZP}, \mathrm{VPA}, \mathrm{PB}$ \\
\hline 7 & $\mathbf{M}$ & + & 23 & 11 & 12 & - & - & $\mathrm{D}$ & Mo & - & - & $+\mathrm{Be}$ & LMT, VPA, PB, CNZ \\
\hline 8 & $\mathbf{M}$ & - & 51 & 5 & 8 & 10 & - & $\mathrm{D}$ & Mo & D & - & - & VPA \\
\hline 9 & $\mathrm{~F}$ & + & 25 & 7 & 12 & - & 23 & $\mathrm{D}$ & Mo & - & 1/life & $+\mathrm{Be}$ & PHT, VPA, PB \\
\hline 10 & $\mathbf{F}$ & - & 39 & 10 & - & - & - & W & - & - & - & - & ETS \\
\hline 11 & $\mathbf{M}$ & + & 37 & 16 & 15 & 14 & - & W & $1 /$ life & Mo & - & - & VPA \\
\hline 12 & $M$ & + & 21 & 17 & - & - & - & W & - & - & - & $+\mathrm{Be}$ & VPA \\
\hline
\end{tabular}

Abs = absences; GTCS = generalised tonic-clonic seizures; Abs S = absences status; $\mathrm{Me} / \mathrm{Be}=$ mental and behavioural status; $\mathrm{D}=$ daily; $\mathrm{W}=\mathrm{weekly} ; \mathrm{Mo}=$ monthly; SP = sporadic; VPA = valproic acid; ETS = ethosuximide; PB = phenobarbitone; CBZ = carbamazepine; PHT = phenytoin; LMT = lamotrigine; $\mathrm{DZP}=$ diazepam; $\mathrm{CNZ}=$ clonazepam

back to the time of onset of the epilepsy and at different intervals thereafter were also available. Each patient had at least one video-EEG or ambulatory recording with documentation of absences. In three patients repeat videoEEG recording of seizures was obtained. Sleep EEG was performed in all patients at the time of our study.

\section{Results}

\section{CLINICAL FINDINGS}

These 12 patients represented $1 \cdot 2 \%$ of the 1000 unselected patients or $7 \%$ of the 170 patients with a diagnosis of idiopathic generalised epilepsy referred to our epilepsy clinic during a five year period. The table shows the clinical features of the patients included in the present study. The patients (seven men and five women) had a median age at referral of 38 (range 21-56) years. A positive family history of epilepsy (of idiopathic generalised epilepsy type) or febrile convulsions was present in four patients $(33 \%)$. A specific aetiological factor (birth hypoxia) was reported by two patients $(16 \%)$. Absences began at a median age of 14 (range 4-32) years but three patients had their first absence after the age of 20 .

The absences were characterised by an abrupt loss of contact in all patients associated with eye blinking in four and gestural automatisms in one. The absences were subjectively perceived as brief "blackouts" or momentary "loss of concentration". The degree of impairment of consciousness varied greatly among the patients; three patients were unaware of their absences and only neuropsychological assessment performed during the EEG discharges disclosed mild disruption of contact and mental slowing. Absences were one to several per day in six patients and occurred at a lower frequency in the remaining patients (once a week in four and once a month in two).

Absence status occurred in four patients $(33 \%)$. In two of them, the status was recorded by video-EEG: in the early phase it consisted of very frequent absence seizures, recurring every 20-30 seconds, and subsequently, it took the form of "absence continuing", with a clinical picture of stupor and confusion. Interestingly a status-like condition was found in the same patients due to hyper- ammonaemia after the start of valproate treatment. A tonic-clonic seizure was sometimes reported at the end of the absence status.

Associated seizure types were described by 10 patients: they consisted of generalised tonic-clonic seizures (10), myoclonic jerks (two), and atonic seizures (one). Tonic-clonic seizures began at a mean age of 18 years.

At the time of referral, six patients were on a single drug regimen, one was taking a combination of two drugs, and five were taking three or more drugs. Nine patients were receiving valproic acid; seven phenobarbitone; two ethosuximide; two phenytoin; two benzodiazepines; one carbamazepine; and one lamotrigine. Anticonvulsant treatment with phenytoin and carbamazepine (which are not usually effective in absence epilepsy) was justified in three patients by the need to control otherwise refractory tonic-clonic seizures.

Neurological examination was normal in all patients. Some degree of cognitive impairment consisting of forgetfulness and mental slowing was noted in three older (over 50 years) patients. Psychiatric disturbances (with aggressiveness, irritability, and impulsive reactions) were seen in three young patients. Brain CT and MRI were normal in all patients.

\section{NEUROPHYSIOLOGICAL FINDINGS}

Waking interictal features at the time of referral

Background activity was normal in all patients. Waking paroxysmal activity was invariably detected in each patient: it consisted of generalised brief $(0.5-2 \mathrm{~s})$ and fast $(3-5 \mathrm{~Hz})$ bursts of spike waves in six patients and of polyspike waves in the remaining cases. Brief runs of polyspikes were also seen in two patients. Associated focal paroxysms were recorded in five. These were short transients of localised sharp waves or spikes, or both. Focal spikes did not precede the generalised paroxysms and could occur in multiple locations in the same or previous EEGs. Hyperventilation increased the generalised abnormalities in all patients whereas intermittent photic stimulation was effective in only three patients.

Sleep interictal features at the time of referral Non-REM sleep phases were obtained in each patient. Paroxysmal abnormalities were increased compared with wakefulness in all patients and consisted of generalised brief 
Figure 1 Sleep interictal paroxysms in two patients. Sleep phase 2: appearance of generalised discharges of multiple spikes. Note the absence of any modification of thoracic breathing, $E C G$, and deltoid surface EMG (right deltoid)
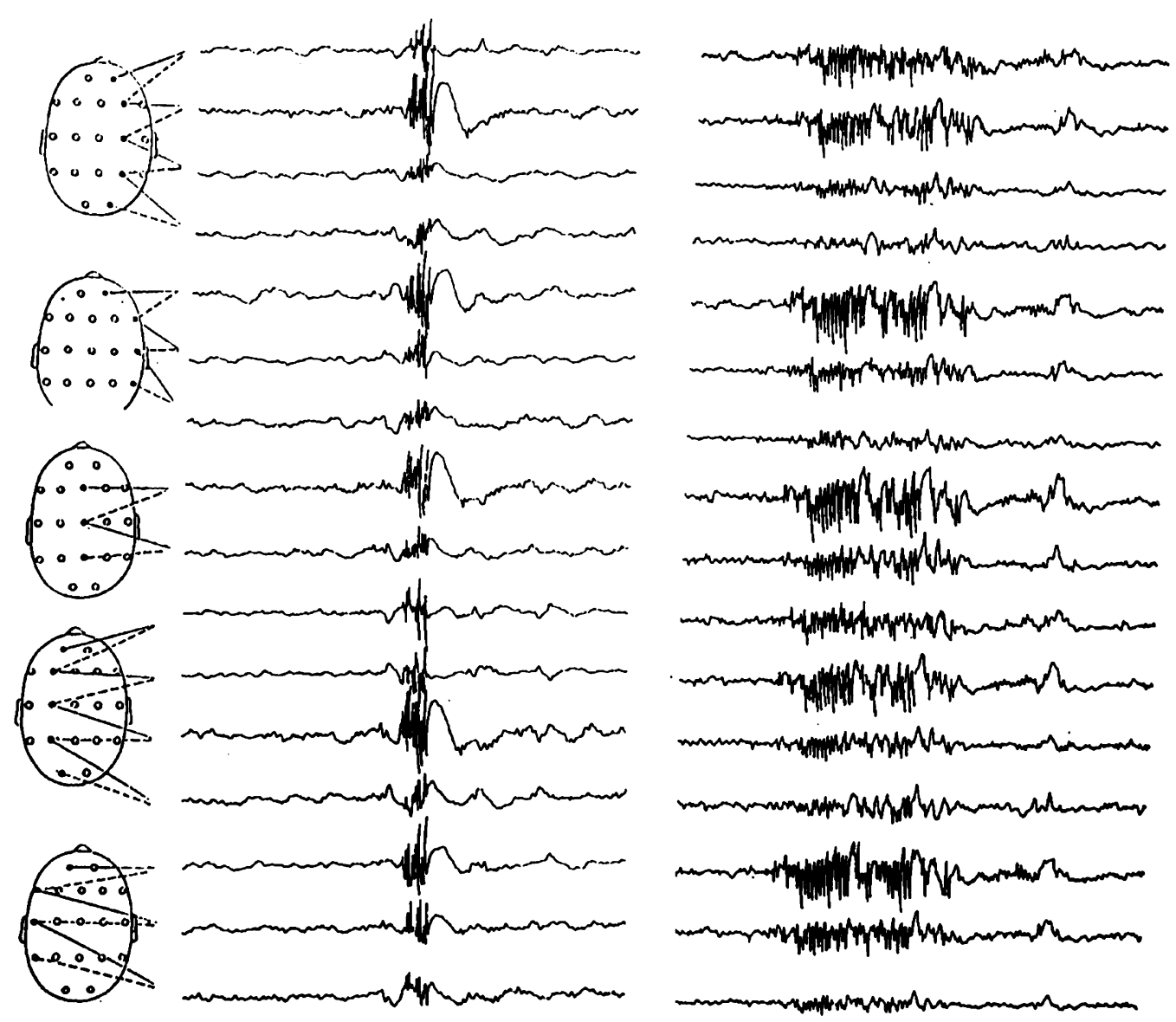

$R$ Deltoid

Thoracic surface EMG breathing

ECG

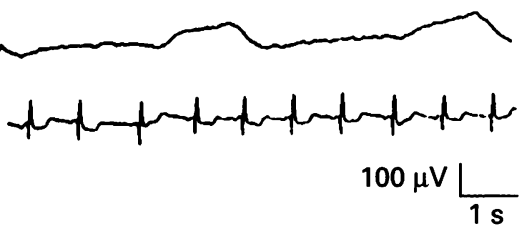

Female aged 25 years 1 March 1994
(0.5-2 s) discharges of spike waves (four), polyspike waves (10), and polyspikes (eight) (fig 1). Associated focal abnormalities were detected in two patients. Long lasting (up to $7 \mathrm{~s}$ ) runs of polyspikes followed by diffuse slowing (with a pattern similar to subclinical tonic seizures) occurred in one patient. REM sleep was not recorded in any patients.

Ictal findings at the time of referral

A total of 40 absences were recorded during video-EEG or ambulatory EEG sessions. In each patient 1 to 10 seizures were available for analysis. The ictal patterns were subdivided into the following categories: (type A) generalised spike wave discharge at $3-4 \mathrm{~Hz}$ with anterior predominance and abrupt onset and end ( 10 seizures in three patients); (type B) generalised spike wave or polyspike wave discharge at $3-4 \mathrm{~Hz}$ beginning with a brief $(0.5-2.5 \mathrm{~s})$ fast activity (polyspikes at 13-14 $\mathrm{Hz}$ ) (19 seizures in six patients) (fig 2); (type C) generalised ictal event in which sequences of polyspikes were intermingled with spike waves or polyspike waves at $3-4 \mathrm{~Hz}$, showing discharge fragmentation and variation of intradischarge frequency (11 seizures in three patients) (fig 2).

In two patients, the coexistence of absences of type B and C was found (fig 2). The absences lasted from three to 60 seconds, the longest duration being found in one patient with seizures of type C. Hyperventilation was an effective activating procedure of absences in 10 patients. Polygraphic variables (particularly surface EMG recording of deltoid muscle) did not show changes concomitant with absences in any patients.

Absence status was recorded by video-EEG in two patients. The EEG features consisted of either short spacing absences of type B or a long lasting condition of continuous spike waves at $2-3 \mathrm{~Hz}$.

\section{Evolution of EEG patterns}

Three patients showing absences of type B (with a brief run of polyspikes preceding the typical discharge of spike waves at $3 \mathrm{~Hz}$ ) at the time of referral had EEG tracings dating back to the period of onset of epilepsy. Two of them, who had their onset of epilepsy at the ages of 5 and 10 years, displayed absences of 

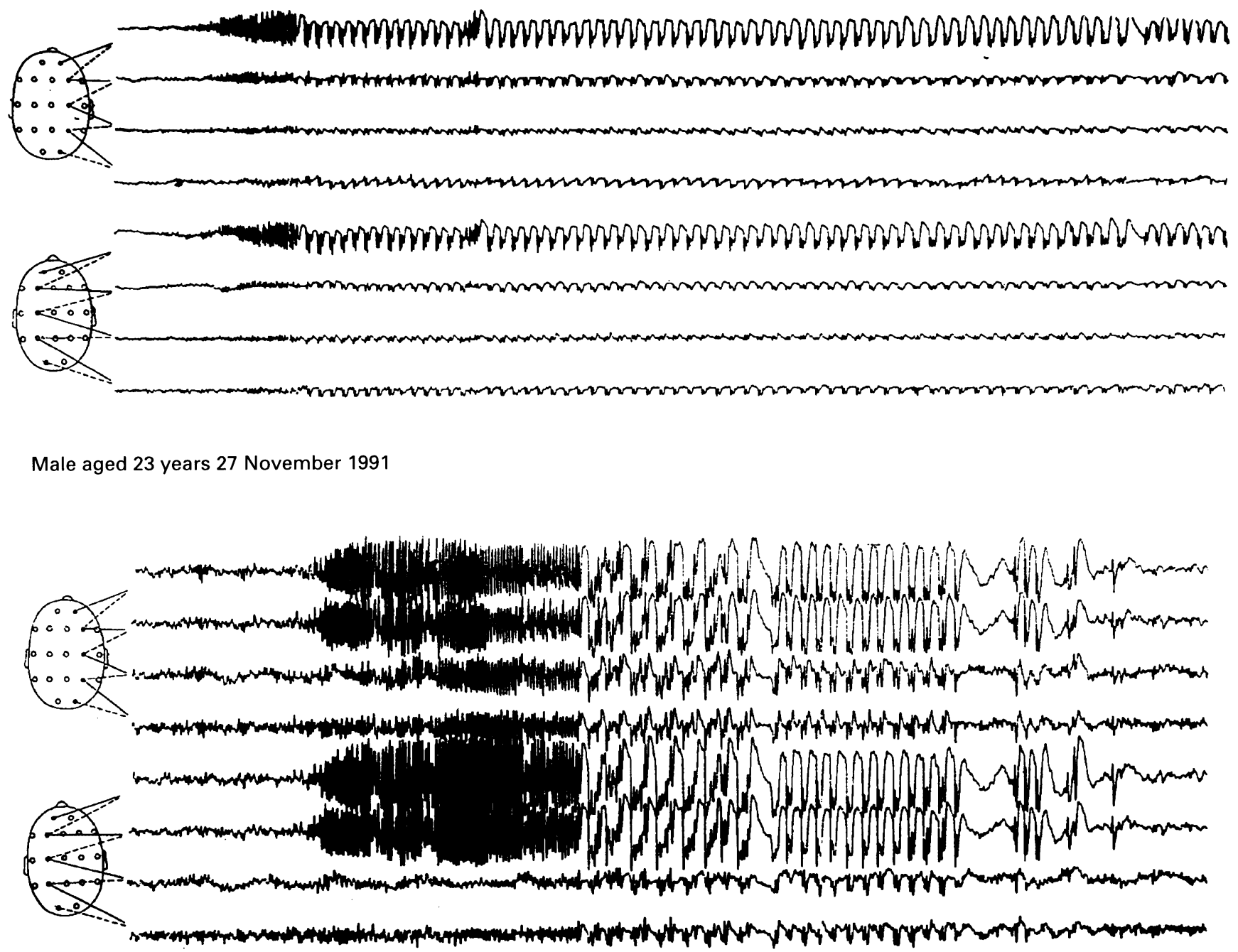

Same male aged 23 years 16 December 1991

$$
100 \mu \mathrm{V} \frac{\mathrm{L}}{1 \mathrm{~s}}
$$

Figure 2 Typical absence seizures of type $B$ and $C$ in a 23 year old man. Upper strip: note the presence of polyspikes at the onset of the spike wave discharge and the long duration of the seizure. Lower strip: a prolonged discharge of polyspikes is followed by polyspike waves and spike waves. Note the fragmentation of the paroxysms and the waxing and waning changes of discharge frequency.

type A (with the typical generalised discharge of spike waves at $3-4 \mathrm{~Hz}$ ) in the early phase of the disease (fig 3). Another patient, with an onset of epilepsy at the age of 16 , showed absences of type B also at the beginning of the disease.

DIAGNOSTIC CONSIDERATIONS

From the analysis of the clinical and neurophysiological findings described above we have tried to classify our patients into syndromic categories according to the proposal of the ILAE. ${ }^{9}$ On the basis of the age of onset of absences, two patients (Nos 2 and 9 of the table) had childhood absence epilepsy and four patients (Nos 4, 6, 10, and 12 of the table) were likely to have juvenile absence epilepsy. Juvenile myoclonic epilepsy was diagnosed in two patients (Nos 8 and 11 of the table) featuring myoclonic jerks as the prominent clinical feature. The remaining four patients had uncertain syndromic classification: indeed three (Nos 1, 3, and 5 of the table) had late onset absences (after the age of
20) and an additional patient (No 7 of the table), although reporting absences since adolescence, displayed high resistance to treatment, associated atonic seizures, and behaviour disturbances, making the diagnosis of juvenile absence epilepsy difficult.

\section{Discussion}

We suggest that our patients were true examples of idiopathic generalised epilepsy. Indeed the general criteria for the diagnosis of idiopathic generalised epilepsy as defined by the Commission of the ILAE ${ }^{9}$ were met in each of our patients: the generalised clinical expression of the seizures, the generalised EEG pattern of the seizures, the absence of neurological or neuroradiological signs, the interictal EEG findings (normal background activity and generalised discharges at $3 \mathrm{~Hz}$ or more), and the increase of the paroxysms during nonREM sleep. The diagnosis of a specific idiopathic generalised epilepsy syndrome could be reliably made for most of our patients, juvenile 


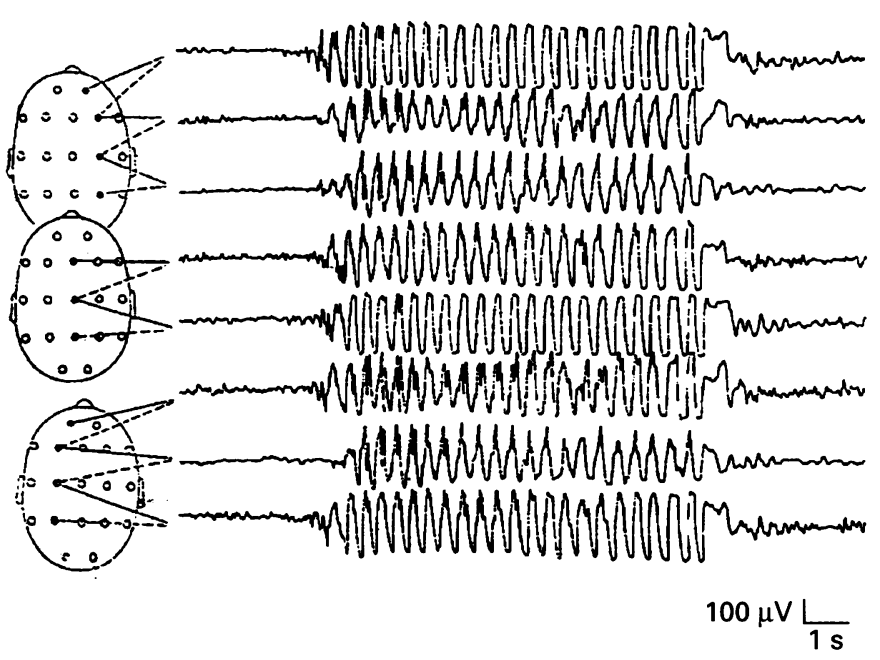

Female aged 13 years 12 December 1969
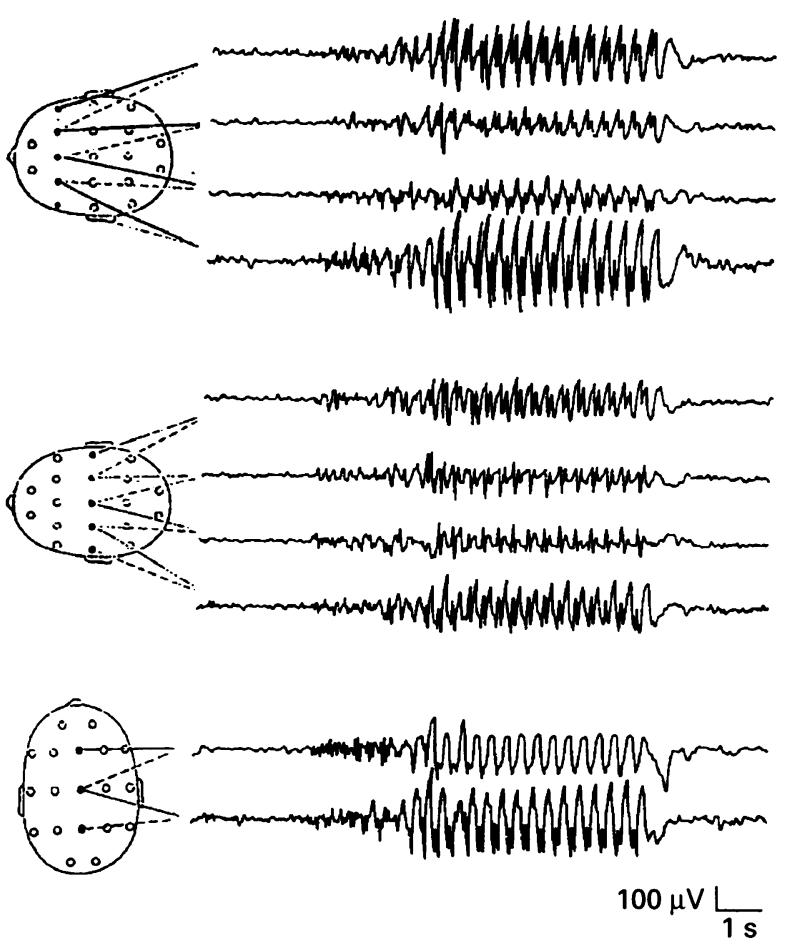

Same female aged 38 years 19 November 1994

Figure 3 Evolution of EEG in one patient, with onset of absences at the age of 10. Note that the absences were characterised by generalised spike wave discharges at 3-4 Hz at the age of 13 (left); 25 years later the absences consisted of a generalised spike wave discharge preceded by multiple spikes (right).

absence epilepsy being the most frequent condition encountered in the present series. This finding is somewhat at variance with the results described by Panayiotopoulos et $a l^{6}$ who reported a high incidence of juvenile myoclonic epilepsy in adult patients with persisting absences. In our series, four patients could not be classified with confidence, mostly because of an exceedingly late onset of absences. It may well be, however, that in some patients absences may escape detection for a long time due to their subtle clinical correlate (phantom absences). ${ }^{67}$ The prevalence of $1.2 \%$ of typical absences found in adults in this study is difficult to compare with other published reports. The epidemiological data mainly reflect the type of population referred to our epilepsy clinic-that is, usually adult and drug resistant epileptic patients with a long history of seizures, therapeutic, and sometimes diagnostic problems.

In our study, several clinical and neurophysiological features deserve special emphasis. Clinically, the semiology of absences, the frequency of associated tonic-clonic seizures, the high incidence of petit mal status, and cognitive and psychiatric problems were distinctive findings.

Absences seemed to be typical from a clinical point of view, as they were characterised by an abrupt loss of contact, sometimes accompanied by eye blinking. Their duration and degree of impaired consciousness varied greatly among patients. In several cases the duration did not exceed three to five seconds and the loss of contact could be detected only after a neuropsychological assessment during the spike wave discharges. Panayiotopoulos et $a l^{67}$ also emphasised that absence seizures in adults are more difficult to recognise than in children, due to their short duration and mild degree of impaired consciousness.

Tonic-clonic seizures occurred in $83 \%$ of our patients. A similar incidence was already reported by other investigators in cases of absences persisting into adult life $\mathrm{e}^{4-7}$; indeed most of our patients began to have absences after the age of 10 years and this later onset absence epilepsy is more likely to be associated with generalised convulsions. ${ }^{13}$ On the other hand the occurrence of this seizure type in patients with absences is widely considered a factor forecasting the persistence of epilepsy and resistance to treatment. ${ }^{710}$

Absence status occurred at some time in a third of our patients and was recorded by video-EEG in two patients. It took the form of "absence continuing" often preceded by a pronounced increase of absences and followed by a tonic-clonic seizure. Although absence status may occur at any age, ${ }^{11}$ it has been reported to occur more often in adulthood, ${ }^{4612}$ sometimes appearing de novo in previously non-epileptic patients. ${ }^{11}$ Panayiotopoulos et $a l^{6}$ argued that in cases of "late onset absence status" without a known history of epilepsy, accurate clinical observation may disclose phantom absences.

Cognitive disturbances consisting of forgetfulness and mental slowing without evidence of intellectual deterioration were noted in three older patients, two of them exhibiting frequent episodes of petit mal status and 
hyperammonaemia related stupor. Gastaut et $a l^{5}$ have also reported a high incidence of late onset psychomotor slowing in their series of adults with persisting absences and noted that this finding was almost exclusively present in female patients with long term treatment with combined drugs. Conversely, in our experience frequent absences and repeated episodes of absence status seem to predispose to mental slowing; age and metabolic factors (hyperammonaemia related to valproate treatment) could also play a part. Psychiatric and behavioural problems consisting of aggressiveness, impulsive reactions, and irritability were found in three young patients. Psychiatric problems have been reported to occur in $29 \%$ of patients with absence epilepsy, ${ }^{2}$ which is similar to that in our series. Recent data on psychosocial adjustment in young adults with absence epilepsies indicate that even this medically benign condition has a great impact on patients' lives. ${ }^{13}$

Evaluation of EEG in our patients also disclosed distinctive features including preservation of a normal background activity, persistence of interictal generalised paroxysms increased by hyperventilation in routine records, independent focal spikes, activation of the abnormalities (mostly in the form of polyspikes or polyspike waves) during slow sleep, and peculiar ictal patterns.

Background activity has been reported to remain normal after many years of seizures in idiopathic generalised epilepsy. ${ }^{25}$ In our patients interictal waking paroxysms were identical to those found in typical idiopathic generalised epilepsy although an excess of polyspikes was often detected. Focal spikes, occurring as independent abnormalities with a high tendency to change in location during the same or following tracings, are not surprising as they have been reported and accepted in true generalised epilepsy. ${ }^{14} 15$ The preponderance of fast paroxysmal activities during sleep is unusual in idiopathic generalised epilepsy and is classically reported in secondary generalised epilepsies. However, sleep patterns in adult idiopathic generalised epilepsy have not been reported so far.

In most of our patients ictal patterns of absences were peculiar in that they showed either a brief run of polyspikes preceding the typical generalised discharge at $3-4 \mathrm{~Hz}$ or more complex patterns with sequences of polyspikes intermingled with spike waves and changes of frequency or discharge fragmentation. Such EEG patterns in absences have rarely been mentioned in the medical literature and have never been described in detail. De Castro et $\mathrm{al}^{16}$ noted the loss of rhythm of the spikes and waves or the variable frequency of the discharge during a single attack. OllerDaurella ${ }^{17}$ described the appearance of polyspikes, either in the interictal tracing or before the spike wave disharge, in patients having absences at the time that grand mal attacks appeared. Similar findings were occasionally mentioned by Livingston et al, ${ }^{1}$ Gastaut and Tassinari, ${ }^{18}$ Gastaut et $a l^{, 5}$ and Panayiotopoulos et $a l^{6}$ in adult patients with idiopathic generalised epilepsy.

The pathophysiology of these multiple spikes in idiopathic generalised epilepsy is unknown. An excess of fast rhythms is sometimes linked to treatment with benzodiazepines but these were given to only two patients in our series. We think that these ictal features are typical of absences persisting in adult life and indicate resistance to treatment or evolution toward grand mal epilepsy.

These clinical and neurophysiological findings may give rise to problems of differential diagnosis, mainly with frontal lobe epilepsy. ${ }^{19}$ It has been known for a long time that frontal lobe epilepsy may at some stage of its evolution mimic idiopathic generalised epilepsy both from a clinical point of view and on EEG. Clinically the three seizure types encountered in idiopathic generalised epilepsy (absences, tonic-clonic seizures, and massive myoclonias) have been found in frontal lobe epilepsy. ${ }^{20-22}$ Electrically the ictal and interictal manifestations of frontal lobe epilepsy may have the same semiology as idiopathic generalised epilepsy. ${ }^{1923}$ Roger and Bureau ${ }^{19}$ suggested that, when unequivocal electroclinical signs are lacking, frontal lobe epilepsy may be suspected in patients who do not fit one of the specific idiopathic generalised epilepsy syndromes classified in the ILAE proposal. ${ }^{9}$

In our patients a reliable diagnosis of idiopathic generalised epilepsy specific syndrome could be made in eight patients and was uncertain only in four. Abnormalities on EEG in patients with frontal lobe epilepsy, although apparently generalised, usually take the form of secondary bilateral synchrony - that is, focal epileptiform discharges followed by bursts of bilateral synchronous spike wave complexes. ${ }^{24}$ In five of our patients focal abnormalities on EEG occurred in combination with the generalised paroxysms. However, the focal spikes never preceded the generalised discharges, as commonly seen in secondary bilateral synchrony, but occurred as independent abnormalities with a high tendency to change in location during the same or subsequent tracings. Moreover, isolated focal EEG abnormalities have been found in cases of true childhood absence epilepsy. ${ }^{1415}$

In conclusion, we have reported the clinical and EEG features of idiopathic generalised epilepsy with absences persisting or recurring into adult life, which seem to be different from those usually found in infancy or adolescence. We suggest that these findings are distinctive and deserve consideration for proper diagnosis and treatment.

This work was partially made possible by grants from Progetto Telethon E 109 , Ministry of Health (40\% funds), and CNR (grant No 942920)

1 Livingston S, Torres J, Pauli LL, Rider RV. Petit mal epilepsy: results of a prolonged follow-up study of 117 patients. $\mathcal{F} A M A$ 1965;194:227-32.

2 Loiseau P, Pestre M, Dartigues JF, Commenges D, Barberger-Gateau C, Cohadon S. Long term prognosis in two forms of childhood epilepsy: typical absence in two forms of childhood epilepsy: typical absence seizures and epilepsy with rolandic

3 Sato S, Dreifuss FE, Penry JK, Kirby DD, Palesch Y. Long-term follow-up of absence seizures. Neurology 1983;33:1590-5. 
4 Gibberd FB. The prognosis of petit mal in adults. Epilepsia 1972;13:171-5.

5 Gastaut H, Zifkin BG, Mariani E, Salas Puig J. The longterm course of primary generalized epilepsy with persisting absences. Neurology 1986;36:1021-8.

6 Panayiotopoulos CP, Chroni E, Dascalopoulos C, Baker A, Rowlinson S, Walsh $P$. Typical absence seizures in adults: clinical, EEG, video-EEG findings and diagnostic adults: clinical, EEG, video-EEG findings and diagnostic syndromic considera

7 Panayiotopoulos CP, Giannakodimos S, Chroni E.Typical absences in adults. In: Duncan JS, Panayiotopoulos CP, eds. Typical absences and related epileptic syndromes. London: Churchill 1995:289-99.

8 Commission on Classification and Terminology of the International League Against Epilepsy. Proposal for revised clinical and electroencephalographic classification of epileptic seizures. Epilepsia 1981;22:489-501.

9 Commission on Classification and Terminology of the International League Against Epilepsy. Proposal for classification of epilepsies and epileptic syndromes. Epilepsia 1989;30:389-99.

10 Dieterich E, Doose H, Baier WK, Fichsel H. Longterm follow-up of childhood epilepsy with absences. II. Absenceepilepsy with initial grand mal. Neuropediatrics epilepsy with

11 Porter RJ, Penry JK. Petit mal status. In: Delgado-Escueta AV, Wasterlain CG, Treiman DM, Porter RJ, eds. Status epilepticus: mechanisms of brain damage and treatment,
Advances in Neurology, Vol 34. New York: Raven Press, 1983:61-7.

12 Rutti W. Absensen-epilepsie im erwachsenenalter. Schweiz Med Wochenschr 1982;112:434-41.

13 Olsson I, Compenhausen G. Social adjustment in young adults with absence epilepsies. Epilepsia 1993;34:846-51.

14 Gastaut H, Broughton R, Roger J, Tassinari CA. Generalized non-convulsive seizures. In: Magnus $\mathrm{O}$, Lorentz De Haas, eds. The epilepsies, handbook of clinical neurology. Amsterdam: North-Holland Publishing Company, 1974:130-44.
15 Gomez MR, Westmoreland BF. Absence seizures. In: Luders H, Lesser RP, eds. Clinical medicine and the nervous system: epilepsy: electroclinical syndromes. New York: Springer Verlag, 1987:105-29.

16 De Castro P, Sacristan J, Moya G, Sanabra F. Phénomènes interparoxystiques dans les tracés EEG présentant des décharges pointe onde bilatérales et synchrones. Rev Neurol 1956;94:882-8.

17 Oller-Daurella L. Contribucion al estudio de las ausencias epilépticas. Evolucion clinica y EEG de 109 casos de ausenepilepticas. Evolucion clinica y EEG de 109 casos de ausencias, seguidas a traves de un periodo de tiempo que oscila entre 10 y 20 anos de observacion person
University of Barcelona, 1967.

18 Gastaut H, Tassinari CA. Epilepsies. In: Remond A, ed. Handbook of electroencephalography and clinical neurophysiology, Vol 13. Clinical EEG III, part A. Amsterdam: Elsevier, 1975:13A:1-13A:104.

19 Roger J, Bureau M. Distinctive characteristics of frontal lobe epilepsy versus idiopathic generalized epilepsy. In Chauvel P, Delgado-Escueta AV, Halgren E, Bancaud J, eds. Frontal lobe seizures and epilepsies, Advances in Neurology. Vol 57. New York: Raven Press, 1992:339-410.

20 Rasmussen T. Characteristics of a pure culture of frontal lobe epilepsy. Epilepsia 1983;24:482-93.

21 Saint-Hilaire JM, Giard N, Bouvier G, Labrecque R. Anterior callosotomy in frontal lobe epilepsies. In: Reeves $\mathrm{AG}$, ed. Epilepsy and the corpus callosum. New York: AG, ed. Epilepsy and the corpus callosum. New York:

Plenum Press, 1985:303-14.

Swartz BE. Pseudo-absence seizures: a frontal lobe phenomenon. F Epilepsy1 992;5:80-93.

23 Bancaud J,Talairach J, Morel P, et al. "Generalized" epileptic seizures elicited by electrical stimulation of the frontal lobe in man. Electroencephalogr Clin Neurophysiol 1974;37:275-82.

24 Gastaut H, Zifkin B, Magaudda A, Mariani E. Symptomatic partial epilepsies with secondary bilateral synchrony: differentiation from symptomatic generalized epilepsies of the Lennox-Gastaut type. In: Wieser HG, Elger CE, eds. Presurgical evaluation of epileptics. Berlin: Springer Verlag, 1987:308-16. 